\title{
Efficiency and equity of orbital motorways in Madrid
}

\author{
Juan Carlos Martín \\ Universidad de Las Palmas de Gran Canaria ${ }^{\text {a }}$ \\ Javier Gutiérrez \\ Universidad Complutense de Madrid
}

\author{
Juan Carlos García-Palomares \\ Universidad Complutense de Madrid \\ Concepción Román \\ Universidad de Las Palmas de Gran Canaria
}

\begin{abstract}
Orbital motorways are major structuring elements in the metropolitan areas of developed countries. They can be considered as key components within the transport network of large urban agglomerations, funneling a great amount of intra- and inter-metropolitan traffic. This paper explores the equity and efficiency effects of orbital motorways on accessibility, using the beltways of Madrid as a case study. It is well known that orbital impacts differ depending on their location within the metropolitan area (inner and outer) as well as the activity distributional performance (agglomeration vs. decentralization of activities). These topics have received very little attention in previous studies. The paper extracts some policy considerations with respect to accessibility disparities within metropolitan areas and compares relative changes from the spatial perspective.
\end{abstract}

Keywords: Orbital motorways, accessibility, Geographic Information Systems (GIS), transport planning.

\section{Introduction}

Orbital motorways are major structuring elements in contemporary metropolitan areas. Empirical evidence shows that the building of beltways, together with an increase in congestion in city centres, has brought about substantial changes in the distribution of intra-metropolitan accessibility. The most accessible points by car are no longer located in the centre of the city; because accessibility is often highest along the orbital corridors, much of the suburban decentralization process has gravitated towards these areas (Muller 1986). Prior to the proliferation of beltways, most movements of goods, services, and people between suburban locations on the highway had to be made via the city centre. As a result, central locations were preferred for many commercial and office functions. The construction of beltways has allowed functions historically concentrated in the central business district (CBD) to locate outside of the central city without losing connectivity within the urbanized area (Sutton 1999). Therefore, these new roads, by improving suburban accessibility, also favour decentralization and the emergence of a polycentric dynamic. With the development of an ubiquitous transport system and the decentralization of both residences and businesses, accessibility has been greatly increased and levels of accessibility have become more homogenous over time (Giuliano 1986).

\footnotetext{
ajcmartin@daea.ulpgc.es
} 
Orbital roads dramatically modify the distribution of accessibility within metropolitan areas. However, empirical studies on the impact of new orbital roads on intra-metropolitan accessibility have been scarce to date. Linneker and Spence (1992a,b) analysed the impact of the London M-25 on inter-metropolitan accessibility. Only the study by Gutiérrez and Gómez (1999) on the Madrid M-40 addressed the effects of intra-metropolitan accessibility distribution, using several indicators and distinguishing between accessibility to the population and to employment (though not between different types of economic activities). This paper goes further than the work of Gutiérrez and Gómez (1999) Gutiérrez and Gómez (1998); it contributes to the literature on accessibility impacts of orbital motorways in the following ways:

- First, the effects on accessibility are analyzed according to the location of orbital motorways (inner and outer).

- Second, the relationship between the geographical distribution of activity and accessibility gains is investigated and the question of whether agglomeration or decentralization plays any significant role is studied.

- Finally, both efficiency and equity perspectives are used to evaluate the different effects of inner and outer orbital motorways.

Our prior hypothesis is that although outer orbitals are used less for intra-metropolitan interactions, they play a very important role in interactions among peripheral municipalities. Outer orbitals usually favour those decentralized activities that have a significant impact in the periphery, and their effects on access to the core activities of the central business district (CBD) are more modest. This paper considers both efficiency (in terms of total accessibility gains and accessibility associated with various forms of economic activity) and equity (whether new orbitals favour inequalities in accessibility between transport zones, which can decisively influence metropolitan structure.

The paper is organized as follows: After this brief Introduction, Section 2 presents a brief review of orbital motorway and accessibility literature and the accessibility indicators used. Section 3 shows the methodology, scenarios and the data considered. Section 4 analyzes the impacts of the construction of two orbital motorways (M40 and M50) on accessibility using a gravity-based indicator using a Geographic Information System (GIS). Finally, Section 5 sets out our conclusions.

\section{Orbital motorways and accessibility}

\subsection{Orbital motorways}

Extensive decentralization of population and employment has occurred in virtually all metropolitan areas in the developed world (Giuliano and Small 1999). As a result of this decentralization process, traffic flows between suburbs have increased dramatically, largely channeled through orbital motorways, which provide the only high-capacity circumferential traffic routes in many major cities. Orbital motorways, in turn, improve the accessibility of suburban municipalities, increasing the value of their locations and making them more attractive to investors, which encourages further decentralization. Thus, orbital motorways favour the decentralization of activities at the same time as the increased flows between suburbs cause progressive congestion of these roads, giving rise to demand for new orbitals farther from the city center. There is no specific causal relationship, but a constant interaction between transport infras- 
tructure, metropolitan structure, and travel demand (e.g. Levinson and Karamalaputi 2003a,b; Parthasarathi et al. 2003).

Orbitals were originally conceived as a means of diverting through traffic away from congested central-city areas, but as they took on more and more local traffic, the role of beltways shifted from inter-urban routes to intra-urban arterials (Sutton 1999). As a result, they have increasingly become integral parts of the intra-metropolitan highway system in areas where they have been constructed (Giuliano 1986).

Despite the fact that orbital motorways are major structuring elements in metropolitan areas, they have so far been given scant attention in academic literature, particularly during the last decade. Of course, there are a few papers that deal with specific aspects of orbital motorways: their origin and evolution (Hall 1990); operational control (Wootton 1990); traffic jam formation on ring roads (Guan and Hu 2005); effects on traffic and mobility (Kroes et al. 1996; Lian 2005); impacts on property values (Langley 1976, 1981; Palmquist 1980); land use and urban development impacts (Baerwald 1978; Gago et al. 2004; Lathrop and Cook 1990; Mattson and Sjölin 2002; Payne-Maxie Consultants 1980; Sutton 1999; van Nes 2001) (Baerwald, 1978); regional development effects (Linneker and Spence 1996); environmental impacts (Li and Tao 2004; Monzon and Villanueva 1996). Only Linneker and Spence (1992a,b) and Gutiérrez and Gómez (1999) have attempted to assess the effects of orbitals on accessibility (inter-metropolitan and intra-metropolitan, respectively). This study extends the state of the art by comparing the accessibility effects of inner and outer orbitals, taking into account the degree of activity decentralization within the metropolitan area.

\subsection{Accessibility and equity}

Among transport planners, the concept of "accessibility" has been gaining momentum for over 50 years. Handy (2002) noted that almost all transportation plans in the United States highlighted "improving accessibility" as a key goal. However, Levinson and Krizek (2005) maintained that the term "accessibility" is often misused and confused with other terms, such as mobility. In contrast to mobility, which refers to the movement of passengers or goods over space, accessibility refers to the ability to reach a destination or ensemble of destinations from a given place using a transport system. According to Hansen (1959), accessibility can be defined as "the potential of opportunities for interaction."

Historically, accessibility has been analyzed using a variety of different indicators that encapsulate different aspects of this multifaceted concept (Black and Conroy 1977; Handy and Niemeier 1997; Jones 1981; Reggiani 1998). van Wee et al. (2001) classifies accessibility indicators into four groups:

- Infrastructure indicators are based on the main characteristics of the infrastructure and its use. Examples include speeds on motorways, travel times by train, density of networks in some specific area (such as a municipality or a region), and so forth.

- Location-based indicators analyze accessibility at locations, typically on a macroscopic level, in order to describe the level of accessibility to spatially distributed activities, such as the number of jobs within 30 minutes travel time from origin locations.

- Person-based indicators are founded in space-time geography and analyze accessibility from the viewpoint of individuals, incorporating spatial and temporal constraints. 
- Utility-based indicators analyze the economic benefits that people derive from access to activities, interpreting accessibility as the outcome of a set of transport choices. These indicators are grounded in utility theory, which addresses the decision to purchase one discrete item from a set of potential choices, all of which satisfy essentially the same need.

This paper evaluates the effects of orbital motorways in Madrid using a location-based measure: economic potential, the most common accessibility indicator. It can be interpreted as the volume of economic activity to which a location has access, after the cost/time of covering the distance to that activity has been accounted for. Economic potential is a gravity model that takes into account two different variables: mass and distance. In our study, distance is measured as travel time and mass as total employment, i.e.:

$$
P_{i}=\sum_{j=1}^{n} \frac{m_{j}}{t_{i j}^{x}}
$$

where $P_{i}$ is the economic (market) potential of node $i, m_{j}$ is the mass (in our case, jobs in each of the economic activities considered) of the centroid $j, t_{i j}$ is the travel time by the minimumtime route along the network between origin $i$ and destination $j$, and $x$ is a parameter that reflects the effect of the distance decay function. In this paper, as in the majority of accessibility studies, the value of the parameter $x$ is 1 .

Accessibility is important not only from an economic perspective, but also from a social perspective. The ability to access to employment, health care, education, and services is critical to the welfare of a population (Leck et al. 2008). Accessibility can be seen as a proxy for measuring welfare, if we accept that the welfare of individuals is related to the ease with which they can access essential services (Hay 1993). Improving accessibility provides individuals with a wider set of opportunities from which to select those best matching their needs and preferences (López et al. 2008).

The concept of accessibility allows us to establish links between transportation and equity. Equity is concerned with the spatial distribution of income and of the resources that affect people's opportunities and quality of life (Leck et al. 2008). The increase or decrease of disparities can be measured by inequality indices employed in economic literature (Cowell 1995), such as the coefficient of variation. Many studies have analyzed the disparities among social groups with regard to accessing services and employment (e.g. Dobbs 2005; Pickup and Giuliano 2005; Pucher and Renne 2003). Other studies have approached this issue from the point of view of accessibility inequalities among places; their underlying assumption has been that transport infrastructure investments will result in positive (or negative) equity effects if they reduce (or increase) existing disparities/inequalities in the spatial distribution of accessibility (e.g. Gutiérrez and Gómez 1999; López et al. 2008). This approach is particularly relevant from the point of view of metropolitan development. New infrastructure, such as orbital motorways, can have important effects on metropolitan structure because a reduction in the accessibility disparities between transport zones favours urban sprawl and decentralization. By reducing travel times between the origins and destinations it connects, a new orbital can increase accessibility in peripheral municipalities; as a result, more activities - some of which may have shifted from formerly favoured locations - will be attracted to these areas (Giuliano 1986). This trend may be unsustainable, however, due to the very high associated environmental costs. In this paper, we analyze the accessibility impacts of inner and outer orbital motorways from the perspective of disparities between places. 


\section{Methodology, scenarios, and data}

A Geographic Information System (ArcGIS) was used to store the socio-economic and network data and to calculate the accessibility indicators. A relatively dense road network was used, taking into account specific arc attributes such as length, number of lanes, speed, and travel time. The network consists of 1312 arcs and 609 nodes covering the whole metropolitan area of Madrid. All metropolitan area roads were taken into account, as well the main streets of the city of Madrid. Figure 1 shows the road network considered.

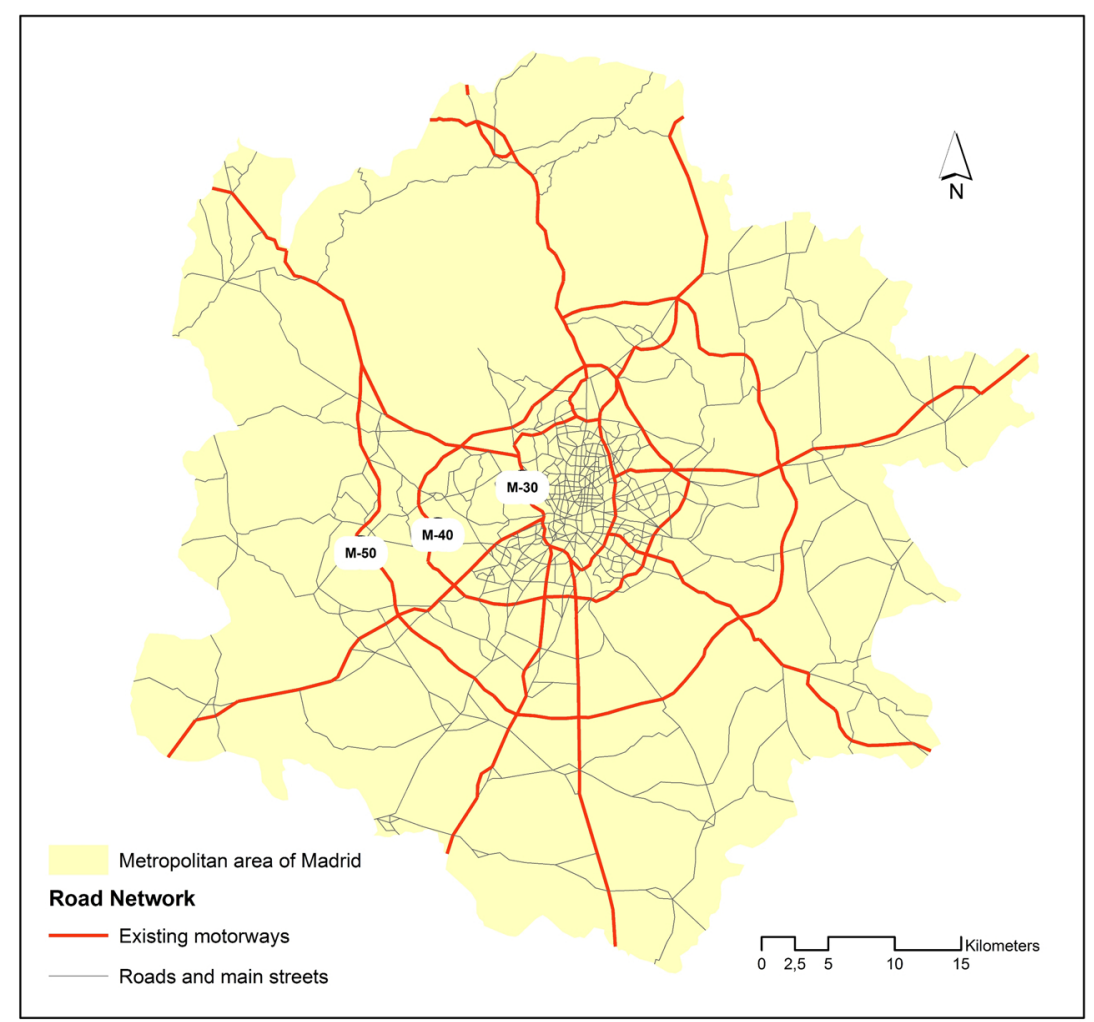

Figure 1: Road network of Madrid.

The area was divided into 69 zones, corresponding to the 21 districts of the municipality of Madrid and the 48 suburban municipalities. Population and employment data were stored for each of the centroids of the zones. The 69 zones were grouped into four rings in order to facilitate summarizing the results of our analysis according to the relative position to the orbitals:

First ring (Inner Madrid): Zones within the M30 (central districts of the municipality of Madrid).

Second ring (Outer Madrid): Zones between the M30 and the M40 (peripheral districts of the municipality of Madrid). 
Third ring (Inner ring of suburban municipalities): Zones between the M40 and the M50.

Fourth ring (Outer ring of suburban municipalities): Area outside the M50.

It is clear that the construction of an orbital highway can change the economic potential of a transport zone, but the nature and degree of this change depend on how the new infrastructure is used for interactions with other transport zones. This is what we wish to assess by developing and comparing different scenarios. Thus, in order to simulate the effect of the orbital motorways, three evaluation scenarios were considered:

M30: the only orbital motorway in the network is the M30,

M40: two orbitals, M30 and M40, are taken into account, and

M50: the three orbital motorways of the metropolitan area are considered.

Changes between the M30 and M40 scenarios show the contribution of the M40 to intrametropolitan accessibility; the comparison between M40 and M50 scenarios illuminates changes in accessibility brought about by the construction of the M50 orbital.

These three scenarios were used to evaluate how new orbitals have caused accessibility changes within the metropolitan area without considering land use changes. Impacts were measured using some static point regarding the information on employment; therefore, an analysis of the historical evolution of accessibility in the metropolitan area of Madrid using dynamic variables is beyond the scope of this paper. In order to clarify each scenario, the following assumptions are made:

Scenarios The M40 scenario is the central scenario of our analysis and is the only one which corresponds to a real scenario, in which mass and impedance variables are contemporaneous (the year 1996, when the M40 was completed). From this basic scenario, the M30 and M50 evaluation ("what-if") scenarios were developed by eliminating all the links of the M40 or by adding the new links created by the M50, respectively. Thus, keeping mass variables fixed, impedance variables were changed according to the physical characteristics of the different networks (orbitals) considered in our analysis. Many other links that were constructed at the same time as the orbital highways were not included; we have only attempted to isolate the changes in accessibility that can be attributed to the construction of the orbitals.

Speeds and travel times The average speed for each arc was recorded for the central M40 scenario according to the official data collected using the floating car method. ${ }^{1}$ In the case of arcs without official data (urban streets and non-principal roads), average speed was estimated taking into account the type of road and the average level of congestion. In order to analyze the impact of structural changes on accessibility, it was assumed that speeds on orbitals do not change with the opening of a new orbital farther from the city center because, according to our experience in Madrid, any such speed increases do not

\footnotetext{
${ }^{1}$ A floating vehicle of the Madrid Council regularly records specific speed data of the sections of the main streets and roads, avoiding extreme traffic conditions (peak hours and valley hours). Average speed for each section is calculated for several time periods (as years) from the individual speed data of the section.).
} 
last long (Gutiérrez and Gómez 1999). The aim of this paper is not to evaluate the impact of short-term changes on accessibility due to temporary alleviation of congestion levels (in terms of travel times), but to analyze the impact of structural changes on accessibility due to the evolution the orbital highway system.

Mass variables Mass variables are the employment in each transport zone according to different sectors of economic activity: industry, retailing, services, and public administration. Employment data correspond to the year 1996 (M40 scenario) and they have been kept constant for the rest of scenarios, in order to analyze the isolated changes that can be attributed to the construction of new orbitals (M40 and M50). The information is based on a mobility survey that was carried out in that year so urban district and municipality data could be obtained. Accessibility to employment is important for workers, but also for businesses that sell intermediate goods and services to other companies.

In short, there are three different scenarios: M40 (the real scenario), and M30 and M50 (the what-if scenarios, developed to compare accessibility changes). Thus, the evaluation of orbital impacts on accessibility considers only the changes in the networks, the remaining elements being kept constant. The decision not to consider changes in land use (which are partly the consequence of the construction of the orbitals) was taken deliberately. Our focus in this paper is on changes in access times caused by the construction of the new infrastructure, not on the by-products of the relocation of activities as a result of new accessibility conditions.

Our prior hypothesis is that the effects of orbitals on accessibility depend, to a large extent, on the location of the orbitals (inner or outer) within the metropolitan area. But the effects are also expected to vary depending on the activities considered. Therefore, four different types of employment were considered, taking into account their different levels of activity agglomeration. As Table 1 shows, employees in the Public Administration and Services sectors are highly concentrated within the first ring (the Central Business District or CBD). On the other hand, employment in the Industry sector is the most dispersed (characterized by a high level of decentralization). Finally, employment in the Retail sector shows an intermediate level of agglomeration, which is similar to that of total employment.

Table 1: Employment distribution by ring in the Madrid metropolitan area.

\begin{tabular}{|c|c|c|c|c|c|c|c|c|c|c|}
\hline \multirow{2}{*}{$\begin{array}{l}\text { Rings } \\
\text { First }\end{array}$} & \multicolumn{2}{|c|}{ Total } & \multicolumn{2}{|c|}{ Industry } & \multicolumn{2}{|c|}{ Retailing } & \multicolumn{2}{|c|}{ Services } & \multicolumn{2}{|c|}{$\begin{array}{c}\text { Public } \\
\text { Administration }\end{array}$} \\
\hline & 759675 & $(44.4 \%)$ & 35803 & $(24.1 \%)$ & 138764 & $(39.4 \%)$ & 110418 & $(59.6 \%)$ & 125547 & $(61.2 \%)$ \\
\hline Second & 364571 & $(21.3 \%)$ & 29729 & $(20.0 \%)$ & 82046 & $(23.3 \%)$ & 33797 & $(18.2 \%)$ & 35846 & $(17.5 \%)$ \\
\hline Third & 308112 & $(18.0 \%)$ & 38269 & $(25.7 \%)$ & 66513 & $(18.9 \%)$ & 24393 & $(13.2 \%)$ & 20918 & $(10.2 \%)$ \\
\hline Fourth & 27891 & $(16.3 \%)$ & 44924 & $(30.2 \%)$ & 64471 & $(18.3 \%)$ & 16774 & $(9.1 \%)$ & 22978 & $(11.2 \%)$ \\
\hline Total & 1460249 & $(100.0 \%)$ & 148725 & $(100.0 \%)$ & 351794 & $(100.0 \%)$ & 185382 & $(100.0 \%)$ & 205289 & $(100.0 \%)$ \\
\hline
\end{tabular}

Source: Consorcio de Transportes de Madrid (1996).

The accessibility indicator was calculated according to the following procedure. First, travel times through the network from each of the origin nodes to each of the 69 centroids were calculated for each of the three scenarios. The accessibility of each transport zone was computed 
by relating travel times with employment data according to the formula shown in Equation 1, setting the value of the travel time exponent equal to 1 . Finally, contour maps were generated by interpolation, and graphs were produced by aggregation of the values of each ring. We will see how the construction of the different orbital motorways has changed the accessibility pattern of all the centroids. It is clear that changes will be more pronounced for those centroids whose interaction with the rest (via minimum-time routes) includes more links with the orbitals under analysis.

\section{Results}

We endeavoured to determine the different accessibility gains patterns for each of the orbitals (inner and outer), as well as for each sector-from Public Administration (where agglomeration of activities is pronounced) to Industry (which is characterized by a more dispersed pattern of activity). This issue has not been previously studied, but it seems clear that both the location of an orbital within the metropolitan area and the level of agglomeration of an economic sector could influence accessibility changes. For the sake of clarity, the results are presented in tables and maps according to the nomenclature of rings that has been previously explained (Section 3). The data were analysed from the twin perspectives of effectiveness and equity:

Efficiency was measured using the average of the gravity-based accessibility indicator within the metropolitan area of Madrid. The interpretation of changes in this indicator average is straightforward: the higher the values, the more efficiency from the point of view of accessibility to employment.

Equity was measured using the coefficient of variation and the Gini index. In this case, decreasing values in the coefficient of variation and Gini index suggest an improvement in spatial equity in terms of accessibility to employment, since inequalities between transport zones tend to be lower.

\subsection{Efficiency}

Analyzing the evolution of accessibility to total employment (Table 2), it can be seen that the average increase (12.3\%) produced by the construction of the orbital M 40 is higher than the that produced by the construction of the orbital M50 (2.6\%). In a metropolitan area where employment is concentrated in the center (44\% of Madrid's total employment is within the first ring), the construction of an internal orbital substantially improves accessibility. The M40 is very efficient. The impact of the M50 (external orbital) on accessibility, in contrast, is much smaller.

The construction of the M40 improves accessibility to employment for each of the sectors considered (Tables 2 and 3). Improvements are more important in activities characterized by a greater level of decentralization. Accessibility improvements for the Industry and Retail sectors are roughly 14 percent and 13 percent, respectively. But the gains for more centralized activities are also important: Public Administration and Services both experience accessibility improvements of more than 10 percent. The outer orbital M50 has a modest impact on all sectors, with the most significant improvements in those activity sectors that were more decentralized, like Industry (4.0\%) - an impact that is roughly twice that experienced by Public Administration (1.9\%), a more concentrated sector. 
Table 2: Accessibility: Scenarios and sectors.

\begin{tabular}{lrrrrcc}
\hline & \multicolumn{3}{c}{ Scenario } & & \multicolumn{2}{c}{ Difference (\%) } \\
\cline { 2 - 3 } \cline { 6 - 7 } & M30 & M40 & M50 & & M30 $\rightarrow$ M40 & M40 $\rightarrow$ M50 \\
\hline Total & 86745 & 97434 & 99983 & & 12.3 & 2.6 \\
Industry & 7356 & 8384 & 8721 & & 13.97 & 4.02 \\
Retailing & 17931 & 20224 & 20838 & & 12.78 & 3.04 \\
Services & 9710 & 10796 & 11010 & & 11.18 & 1.99 \\
Public Administration & 10373 & 11502 & 11724 & & 10.89 & 1.93 \\
\hline
\end{tabular}

The most significant accessibility improvements produced by the M40 are located in the areas surrounding the orbital (second and third rings) and in the more decentralized activities (Tables 3 and 4; Figure 2). But the impact of this orbital extends to the metropolitan space as a whole, with major accessibility increases in the first ring (by redistributing internal movements, it improves relations with the first ring) and in the fourth (by facilitating relations between the fourth ring and the other rings).

The construction of the M50 has also had more benefits in the areas located near the orbital (third and fourth rings), especially in those nodes located in the fourth ring (Tables 3 and 4; Figure 3). However, the effects of adding this orbital are almost negligible in the two inner rings. The M50 has had a smaller impact because employment is less significant in its surrounding area, particularly in sectors with more centralized employment patterns. It may be concluded that the effects of the M50 on overall accessibility of the metropolitan area of Madrid are not significant in terms of efficiency. However, this situation could change in the near future as new office developments are completed.

\subsection{Equity}

When equity is considered, it may be observed that the two orbitals have had very different effects: the M40 does not change the previous scenario significantly, and even increases the polarization of the spatial distribution of accessibility (the coefficient of variation for total employment increases by $0.8 \%$ ); the M50, however, increases equity among transport zones (the coefficient of variation decreases by 6\%). The Gini index confirms this effect (Table 5).

In the M30 scenario, employment sectors characterized by strong agglomeration effects (such as Public Administration) experience greater polarization than more distributed sectors (such as Industry). Employment in agglomerated sectors tends to be concentrated within the first ring. Accessibility values are very high in the first ring, but decrease sharply from the first ring to the fourth. Meanwhile, industrial activities tend to be distributed more homogenously throughout the metropolitan area, so fewer disparities between different rings in the distribution of accessibility are observed (Table 4).

Changes in accessibility following the construction of new orbitals (M40 in this case) may increase or decrease spatial equity, depending on which transport zones are most strongly affected by the new infrastructure. At first glance, it may appear that all orbitals will, by their nature, tend to equalize accessibility among transport zones (in contrast to radial highways, 
Table 3: Accessibility averages according to scenarios, sectors and rings.

\begin{tabular}{lrrrrr}
\hline Rings & Total & Industry & Retailing & Services & $\begin{array}{c}\text { Public } \\
\text { Administration }\end{array}$ \\
& \multicolumn{5}{c}{ Scenario M30: } \\
\cline { 2 - 6 } First & 136256 & 9588 & 26874 & 16956 & 18198 \\
Second & 118772 & 9555 & 24353 & 13478 & 14301 \\
Third & 94487 & 8233 & 19604 & 10342 & 10947 \\
Fourth & 63622 & 5885 & 13464 & 6790 & 7304 \\
& & & Scenario M40: & \\
First & 146885 & 10521 & 29132 & 18153 & 19445 \\
Second & 134097 & 11057 & 27692 & 14989 & 15910 \\
Third & 113029 & 10032 & 23596 & 12182 & 12856 \\
Fourth & 69763 & 6481 & 14764 & 7418 & 7949 \\
& & & Scenario M50: & \\
First & 146966 & 10548 & 29143 & 18156 & 19452 \\
Second & 134334 & 11092 & 27743 & 15001 & 15928 \\
Third & 116044 & 10446 & 24290 & 12424 & 13115 \\
Fourth & 73309 & 6938 & 15570 & 7725 & 8260 \\
\hline
\end{tabular}

Table 4: Gravity based accessibility changes (\%) between scenarios.

\begin{tabular}{lrrrrr}
\hline Rings & Total & Industry & Retailing & Services & $\begin{array}{c}\text { Public } \\
\text { Administration }\end{array}$ \\
\hline & \multicolumn{5}{c}{ Changes $\mathbf{M} 30 \rightarrow$ M40: } \\
\cline { 2 - 6 } First & 7.8 & 9.7 & 8.4 & 7.1 & 6.9 \\
Second & 12.9 & 15.7 & 13.7 & 11.2 & 11.3 \\
Third & 19.6 & 21.9 & 20.4 & 17.8 & 17.4 \\
Fourth & 9.7 & 10.1 & 9.7 & 9.2 & 8.8 \\
& & & Changes $\mathbf{M 4 0 \rightarrow}$ M50: & \\
First & 0.1 & 0.3 & 0.0 & 0.0 & 0.0 \\
Second & 0.2 & 0.3 & 0.2 & 0.1 & 0.1 \\
Third & 2.7 & 4.1 & 2.9 & 2.0 & 2.0 \\
Fourth & 5.1 & 7.1 & 5.5 & 4.1 & 3.9 \\
\hline
\end{tabular}






Public administration

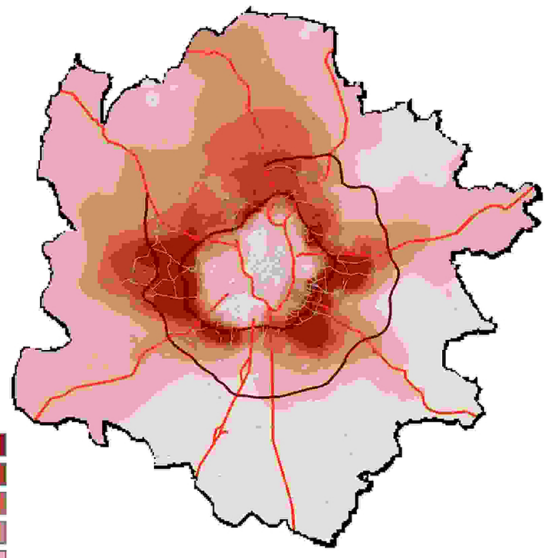

Industry

Figure 2: Percentage change in gravity-based accessibility measure between M30 and M40 scenarios (Public Administration and Industry sectors).

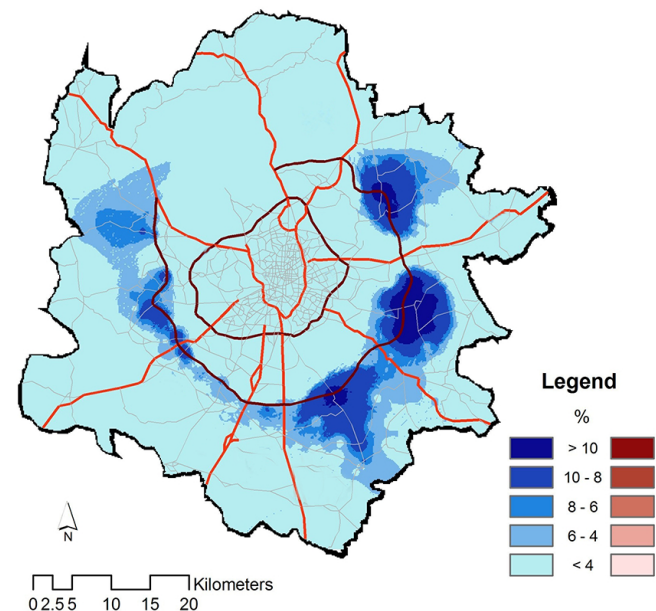

Public administration

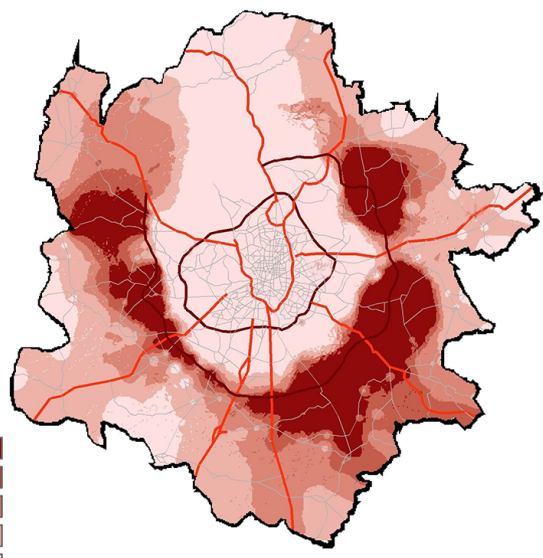

Industry

Figure 3: Percentage change in gravity-based accessibility measure between M40 and M50 scenarios (Public Administration and Industry sectors). 
Table 5: Accessibility and coefficients of variation (CV). Scenarios and Sectors.

\begin{tabular}{|c|c|c|c|c|c|}
\hline \multirow[b]{3}{*}{ Total: } & \multicolumn{3}{|c|}{ Scenarios } & \multicolumn{2}{|c|}{ Changes } \\
\hline & M30 & M40 & M50 & $\mathrm{M} 30 \rightarrow \mathrm{M} 40$ & $\mathrm{M} 40 \rightarrow \mathrm{M} 50$ \\
\hline & & & & & \\
\hline $\mathrm{CV}$ & 34.40 & 34.69 & 32.41 & $0.29(0.84 \%)$ & $-2.28(-6.57 \%)$ \\
\hline Gini & 0.15 & 0.15 & 0.14 & $0.01(3.51 \%)$ & $-0.01(-7.93 \%)$ \\
\hline \multicolumn{6}{|c|}{ Industry: } \\
\hline $\mathrm{CV}$ & 27.92 & 29.46 & 26.99 & $1.54(5.52 \%)$ & $-2.47(-8.38 \%)$ \\
\hline Gini & 0.12 & 0.13 & 0.12 & $0.01(5.69 \%)$ & $-0.01(-9.48 \%)$ \\
\hline \multicolumn{6}{|c|}{ Retailing: } \\
\hline $\mathrm{CV}$ & 32.86 & 33.42 & 30.96 & $0.56(1.70 \%)$ & $-2.46(-7.36 \%)$ \\
\hline Gini & 0.14 & 0.15 & 0.14 & $0.01(3.75 \%)$ & $-0.01(-8.24 \%)$ \\
\hline \multicolumn{6}{|c|}{ Services: } \\
\hline $\mathrm{CV}$ & 39.77 & 39.11 & 37.16 & $-0.66(-1.66 \%)$ & $-1.95(-4.99 \%)$ \\
\hline Gini & 0.17 & 0.17 & 0.16 & $0.00(-1.16 \%)$ & $-0.01(-4.82 \%)$ \\
\hline \multicolumn{6}{|c|}{ Public Administration: } \\
\hline $\mathrm{CV}$ & 39.09 & 38.62 & 36.80 & $-0.47(-1.20 \%)$ & $-1.82(-4.71 \%)$ \\
\hline Gini & 0.17 & 0.17 & 0.16 & $0.00(-1.72 \%)$ & $-0.01(-3.99 \%)$ \\
\hline
\end{tabular}

which tend to favor accessibility to the CBD). However, the results for the M40 contradict this hypothesis because, in fact, the spatial distribution of accessibility is more polarized under its construction. This is partly explained by the intrinsic characteristics of the metropolitan area of Madrid, as the M40 can also be considered an inner orbital benefitting those transport zones that were already highly accessible before its construction (second ring), but the observed effects on transport zones with poor accessibility (fourth ring) or good accessibility (first ring) are similar.

Examining economic activity sectors individually shows that the effects of orbital highway construction vary significantly depending on the characteristics of each sector. The M40 reduces spatial disparities in the sectors that are more centralized, such as Public Administration $(-1.2 \%)$, but increases disparaties in the more dispersed activities like Industry $(+5.5 \%)$. It is evident that this difference is due to the distribution of employment: more than half of Industry jobs are located in the peripheral (third and fourth) rings, in contrast to Public Administration where most employment is concentrated in the first ring. In short, the M40 serves as an inner transport infrastructure component for the more decentralized activities like Industry (producing less spatial equity in accessibility to industrial employment), but serves as an external infrastructure component for more centralized activities such as Public Administration (reducing inequalities in the spatial distribution of accessibility to Public Administration employment). In sectors with decentralized employment (e.g. Industry) improvements are greater in zones with good accessibility, while in centralized sectors (e.g. Public Administration) improvements are greater in zones with low accessibility (Figure 4). At any rate, the correlations 
between accessibility level and improvements are always very slight, which is consistent with the relative insubstantiality of the changes.
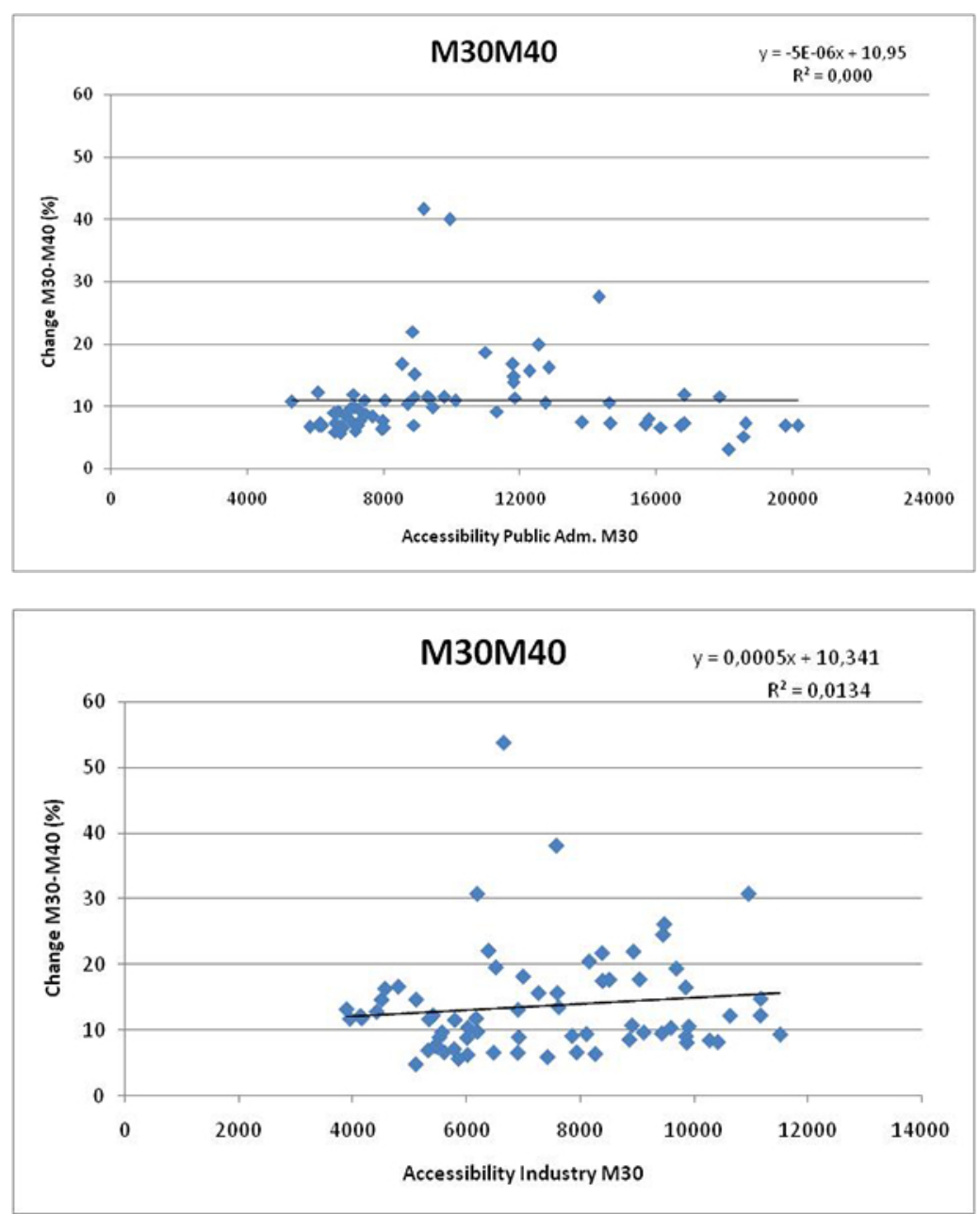

Figure 4: Changes in gravity-based accessibility measure between M30 and M40 scenarios, according to transport zones.

The M50 considerably improves the average accessibility of the transport zones that previously showed lower levels of accessibility, and thereby increases spatial equity among transport zones (Figure 5). In all sectors, the coefficient of variation and Gini index are reduced, and reductions are more significant in those sectors that are decentralized. Reductions range from 8.3 percent for Industry to 4.7 percent for Pubic Administration. In summary, it may be concluded that the equity changes under the M50 scenario are more significant than those observed following the construction of the M40, irrespective of the degree of activity agglomeration.

\section{Conclusions}

In this paper, we have studied accessibility changes produced by the construction of orbital motorways (M40, M50) in Madrid using a gravity-based accessibility measure. This type of 

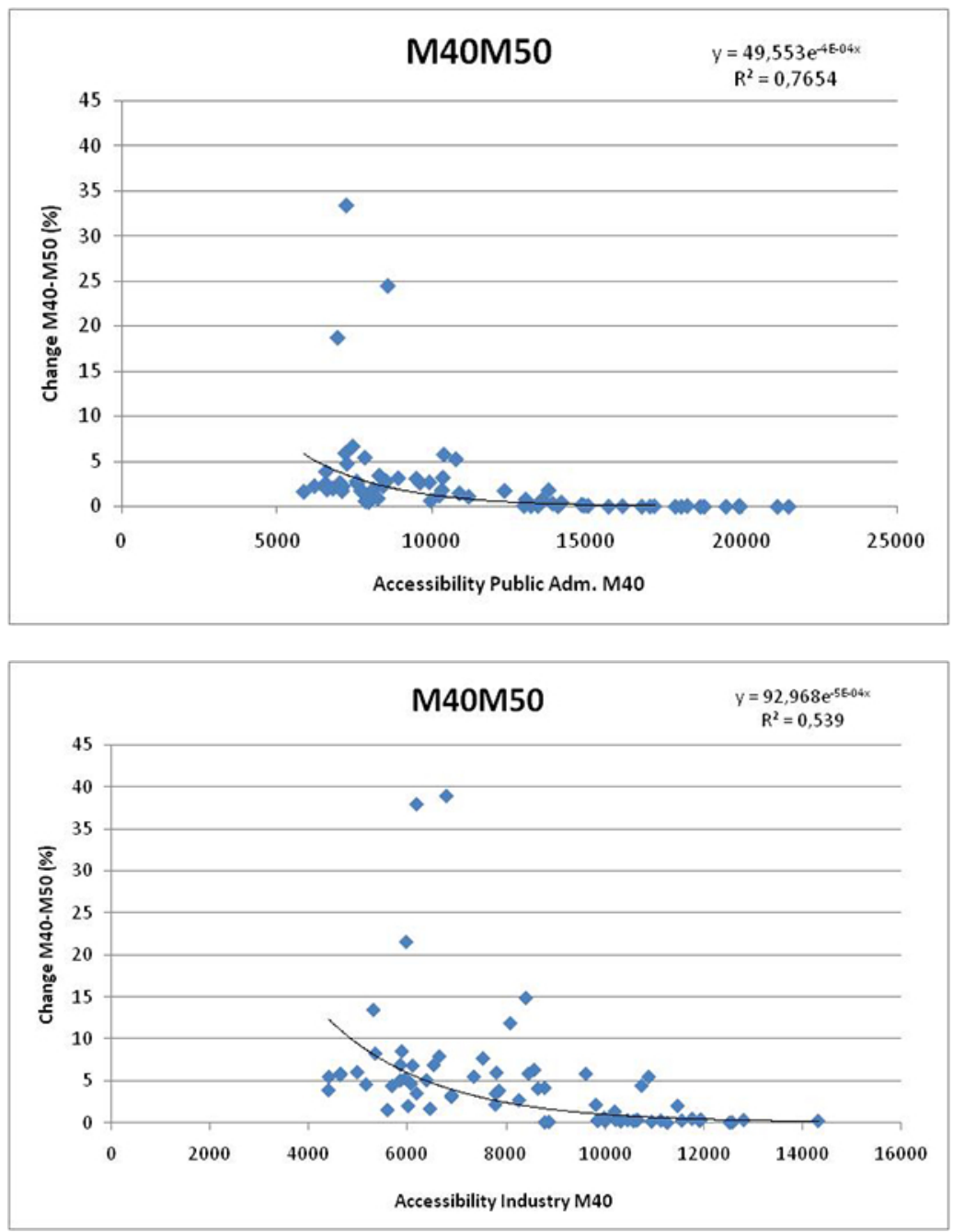

Figure 5: Changes in gravity-based accessibility measure between M40 and M50 scenarios, according to transport zones.

infrastructure has been a predominant form of transportation infrastructure investment in large metropolitan areas in recent years. The construction of orbital motorways over an earlier radial system has created radial-concentric structures. This new topology has dramatically changed accessibility patterns and spatial interaction for municipalities inside metropolitan areas.

In the case of metropolitan Madrid, it has been shown that the effects of new orbitals on accessibility depend heavily on two basic issues: their location and the spatial distribution of employment in the economic sectors under study. Inner orbitals like the M40 support a variety of interactions, and produce many important changes in terms of efficiency. However, the effects of inner orbitals on equity are almost negligible and, in some cases, inner orbitals can even amplify spatial disparities within the metropolitan area. In contrast, outer orbitals (such as the M50) appear to have the opposite effect: their effect on efficiency is much weaker, though they have a significant effect on equity. The explanation for this finding is that a new outer orbital confers greater benefits on those municipalities with lower levels of accessibility. Analyzing the 
overall impact of both orbitals, and taking into account both efficiency and equity perspectives, it may be concluded that the M40 and M50 have dramatically changed accessibility in the metropolitan area of Madrid.

It has also been shown that the spatial distribution of activities in the metropolitan area under analysis is also important. One orbital can play two distinct roles for different activities. The M40 could be considered an inner orbital for decentralized activities, but an outer orbital for centralized activities. In the first case, the changes observed would be very significant in terms of efficiency and almost negligible in terms of equity. The opposite might be true for the second case, that is, small changes in efficiency but very significant changes in equity.

These findings have clear implications for urban planning. Inner orbitals tend to be more effective at addressing efficiency issues, and the associated financial burdens tend to be smaller because the length of the infrastructure is shorter. Considering the structure of the metropolitan area, the most peripheral transport zones receive hardly any benefit from this type of orbital. So, given a planning goal of extending the advantages of the CBD into suburban areas, this type of orbital will be appropriate. On the other hand, outer orbitals like the M50 are not only more expensive but also less efficient in terms of improving accessibility. These orbitals also encourage more decentralization of activities and housing in the metropolitan area, because they particularly favour external transport zones, increasing equity among transport zones in the distribution of access to employment. With regard to questions of environmental sustainability, the typically high environmental costs associated with the construction of outer orbitals renders them controversial. First, these roads directly consume large areas of land and they indirectly bring about new housing and office developments in low density areas. Second, this trend favours metropolitan dispersion, making households more dependant on private vehicles, which once again generates further environmental costs. Thus, taking into account the new induced transport demand and accessibility efficiency considerations, the construction of inner orbitals (if feasible) will be more desirable than the construction of outer orbitals.

In Madrid, as in many other cities of both developed and developing nations, the construction of new orbitals is inducing high levels of residential and commercial development in the surrounding area, significantly modifying the existing metropolitan structure (Gago et al. 2004). There is some evidence that the construction of this type of infrastructure has led businesses to relocate their headquarters from central business districts to well-connected areas near the new orbitals. To give just one example, the headquarters of Telefonica, with 10,000 employees, have been moved to a new location near the M40, and the Santander Bank headquarters (7000 employees) have also moved to a location near the M50. This is a new phenomenon for metropolitan Madrid; previously, the headquarters of big Spanish firms were located in the CBD, near Public Administration offices.

Orbital motorways are major elements of the metropolitan network. They have major impacts on the distribution of intra-metropolitan accessibility and therefore play an important role in the evolution of the structure of cities. However, in this paper some evidence has been obtained regarding how different impacts can be depending on two basic characteristics: orbital location and the degree of activity agglomeration. Trying to reconcile different objectives to promote more livable and sustainable metropolises will be the primary aim of land use planners in the future. 


\section{Acknowledgements}

We want to express our gratitude to the editor and three anonymous referees for helpful comments and suggestions. Financial support from MICINN (TRA2005-06619/MODAL) is gratefully acknowledged.

\section{References}

Baerwald, T. 1978. The emergence of a new downtown. Geographical Review, 68(3):308-318. Black, J. and M. Conroy. 1977. Accessibility measures and the social evaluation of urban structure. Environment and Planning A, 9(9):1013-1031. URL http://www.envplan.com/ abstract.cgi?id=a091013.

Consorcio de Transportes de Madrid. 1996. Encuesta domiciliaria de movilidad.

Cowell, F. A. 1995. Measuring inequality: Techniques for the social sciences. New York: Wiley, 2nd edition.

Dobbs, L. 2005. Wedded to the car: Women, employment and the importance of private transport. Transport Policy, 12(3):266-278.

Gago, C., M. Serrano, and J. Antón. 2004. Repercusiones de las carreteras orbitales de la Comunidad de Madrid en los cambios en los usos del suelo. Anales de Geografía de la Universidad Complutense, 24:145-167.

Giuliano, G. 1986. Land use impacts of transportation investment: Highway and transit. In S. Hanson, ed., The Geography of Urban Transportation, pp. 247-279. New York: The Guilford Press.

Giuliano, G. and K. A. Small. 1999. The determinants of growth of employment subcenters. Journal of Transport Geography, 7(3):189 - 201. doi: 10.1016/S0966-6923(98)00043-X.

Guan, W. and H. Hu. 2005. Qualitative analysis of traffic jam formation in urban ring road. In Proceedings of the 8th International IEEE Conference on Intelligent Transportation Systems.

Gutiérrez, J. and G. Gómez. 1999. The impact of orbital motorways on intra-metropolitan accessibility: The case of Madrid's M-40. Journal of Transport Geography, 7(1):1-15. doi: 10.1016/S0966-6923(98)00029-5.

Hall, P. 1990. Orbital motorways. In Institution of Civil Engineers: Orbital motorways, pp. 1-31. London: Thomas Telford.

Handy, S. L. 2002. Accessibility vs mobility: Enhancing strategies for addressing automobile dependence in the U.S. In European Conference of Ministers of Transport, Tokyo, Japan.

Handy, S. L. and D. A. Niemeier. 1997. Measuring accessibility: An exploration of issues and alternatives. Environment and Planning A, 29(7):1175-1194. URL http://www.envplan. com/abstract.cgi? id=a291175.

Hansen, W. 1959. How accessibility shapes land use. Journal of the American Institute of Planners, 25:73-76.

Hay, A. 1993. Equity and welfare in the geography of public transport provision. Journal of Transport Geography, 1(2):95-101. doi: 10.1016/0966-6923(93)90003-I.

Jones, P. C. 1981. A network model of economic growth: A regional analysis. Regional Science and Urban Economics, 11(2):231-237. doi: 10.1016/0166-0462(81)90006-5.

Kroes, E., A. Daly, H. Gunn, and T. Hoorn. 1996. The opening of the Amsterdam ring road. Transportation, 23(1):71-82. doi: 10.1007/BF00166220. 
Langley, C. 1976. Adverse impacts of the Washington beltway on residential property values. Land Economics, 52(1):54.

Langley, C. J. 1981. Highways and property values: The Washington beltway revised. Transportation Research Record, 812.

Lathrop, G. and K. Cook. 1990. The effect of beltways on urban development: A discussion of US experience. In Institution of Civil Engineers: Orbital motorways, pp. 143-156. London: Thomas Telford.

Leck, E., S. Bekhor, and D. Gat. 2008. Equity impacts of transportation improvements on core and peripheral cities. Journal of Transport and Land Use, 2(1):153-182.

Levinson, D. and R. Karamalaputi. 2003a. Induced supply: A model of highway network expansion at the microscopic level. Journal of Transport and Economics Policy, 37:297-318.

Levinson, D. and R. Karamalaputi. 2003b. Prediciting the construcion of new highway links. Journal of Transportation Statistics, 6:81-89.

Levinson, D. and K. Krizek. 2005. The machine for access. In D. Levinson and K. Krizek, eds., Access to Destinations, pp. 1-10. Netherlands: Elsevier Inc.

$\mathrm{Li}, \mathrm{B}$. and S. Tao. 2004. Influence of expanding ring roads on traffic noise in Beijing City. Applied Acoustics, 65(3):243.

Lian, J. I. 2005. Impact of main road investment in Bergen and Oslo. In 45th Congress of European Regional Science Association. Amsterdam.

Linneker, B. and N. Spence. 1992a. An accessibility analysis of the impact of the M25 London orbital motorway in Britain. Regional Studies, 26(1):31-47.

Linneker, B. and N. Spence. 1996. Road transport infrastructure and regional economic development: The regional development effects of the M25 London orbital motorway. Journal of Transport Geography, 4(2):77-92. doi: 10.1016/0966-6923(96)00001-4.

Linneker, B. J. and N. A. Spence. 1992b. Accessibility measures compared in an analysis of the impact of the M25 London orbital motorway on Britain. Environment and Planning A, 24(8):1137-1154. URL http://www.envplan.com/abstract.cgi?id=a241137.

López, E., G. Gutiérrez, and G. Gómez. 2008. Measuring regional cohesion effects of large-scale transport infrastructure investment: An accessibility approach. European Planning Studies, $16(2): 277-301$.

Mattson, L. and L. Sjölin. 2002. Transport and location effects of a ring road with or without road pricing. In Sixth Workshop of the Nordic Research Network on Modelling Transport, Land-Use and the Environment. Haugesund.

Monzon, A. and J. Villanueva. 1996. Impact of the madrid m-40 ring road on emission from road traffic. Science of the Total Environment, 189-190:119-124. doi: 10.1016/00489697(96)05199-6. Highway and Urban Pollution.

Muller, P. 1986. Transportation and urban form: Stages in the spatial evolution of the American metropolis. In S. Hanson, ed., The geography of urban transportation, pp. 24-48. New York/London: The Guilford Press.

Palmquist, R. 1980. Impact of highway improvements on property values in Washington. Research project HR-6364, Washington State Department of Transportation.

Parthasarathi, P., D. Levinson, and R. Karamalaputi. 2003. Induced demand: A microscopic perspective. Urban Studies, 40(7):1335-1353.

Payne-Maxie Consultants. 1980. The land use and urban developments impacts of beltways. Final Report DOT-OS-90079, Department of Transportaton and Department of Housing 
and Urban Development.

Pickup, L. and G. Giuliano. 2005. Transport and social exclusion in Europe and the USA. In K. Donaghy, S. Poppelreuter, and G. Rudinger, eds., Social dimensions of sustainable transport, pp. 38-49. Aldershot, UK: Ashgate.

Pucher, J. and J. Renne. 2003. Socioeconomics of urban travel: Evidence from teh 2001 NHTS. Transportation Quarterly, 57(3):49-77.

Reggiani, A. 1998. Accessibility, trade and location behavior: An introduction. In A. Reggiani, ed., Accessibility, trade and location behaviour, pp. 1-16. Aldershot, UK: Ashgate.

Sutton, C. J. 1999. Land use change along Denver's I-225 beltway. Journal of Transport Geography, 7(1):31-41. doi: 10.1016/S0966-6923(98)00025-8.

van Nes, A. 2001. Road building and urban change: A morphological and configurative explanation of how ring roads change the pattern of distribution of shops in city and town centres. In Proceedings of the 3rd International Space Syntax Symposium. Atlanta.

van Wee, B., M. Hagoort, and J. A. Annema. 2001. Accessibility measures with competition. Journal of Transport Geography, 9(3):199-208. doi: 10.1016/S0966-6923(01)00010-2.

Wootton, J. 1990. The operational control of motorways. In Institution of Civil Engineers: Orbital motorways, pp. 37-50. London: Thomas Telford. 